Cadernos de Clio, Curitiba, v. 9, nº 1, 2018

\title{
FEDERICI, Silvia. O Ponto Zero da Revolução: trabalho doméstico, reprodução e luta feminista. São Paulo: Elefante, 2018. 388 p.
}

\author{
Eduardo Gern Scoz ${ }^{1}$ \\ Letícia Barreto Assad Bruel ${ }^{2}$ \\ Rafaela Zimkovicz ${ }^{3}$ \\ Vitória Gabriela da Silva Kohler ${ }^{4}$
}

Enquanto os homens enfrentavam a linha de frente nos campos de batalha durante a Segunda Guerra Mundial, as mulheres assumiram os postos de trabalhadoras e provedoras do sustento familiar. A autoconfiança adquirida através deste processo, junto a um ressentimento ocasionado pelas desagregações familiares decorrentes da alta mortalidade do conflito, incentivou a busca por trabalhos alternativos ao do lar, provocando um distanciamento do trabalho doméstico. Este novo aspecto social refletiu nos

${ }^{1}$ Estudante do $7^{\circ}$ período do curso de História (Licenciatura e Bacharelado) na Universidade Federal do Paraná. É bolsista do grupo PET História UFPR e faz Pesquisa Individual sob a orientação da $\operatorname{Prof}^{\mathrm{a}} \mathrm{Dr}^{\mathrm{a}}$ Ana Paula Vosne Martins.

${ }^{2}$ Estudante do $5^{\circ}$ período do curso de História (Licenciatura e Bacharelado) na Universidade Federal do Paraná. É bolsista do grupo PET História UFPR e faz Iniciação Científica sob a orientação da $\operatorname{Prof}^{\mathrm{a}} \operatorname{Dr}^{\mathrm{a}}$ Priscila Piazentini Vieira.

${ }^{3}$ Estudante do $3^{\circ}$ período do curso de História (Licenciatura e Bacharelado) na Universidade Federal do Paraná. É bolsista do grupo PET História UFPR.

${ }^{4}$ Estudante do $3^{\circ}$ período do curso de História (Licenciatura e Bacharelado) na Universidade Federal do Paraná. É bolsista do grupo PET História UFPR. 
trabalhos feministas na década de 1970, cuja ausência do debate sobre a organização da casa se fez notável. ${ }^{5}$

As ideias expressas acima estão contidas na introdução da obra $O$ Ponto Zero da Revolução: trabalho doméstico, reprodução e luta feminista (2018), de Silvia Federici, filósofa, escritora e ativista por um feminismo anticapitalista. Nascida na Itália e radicada nos Estados Unidos, escreve principalmente sobre o trabalho reprodutivo no capitalismo sob uma perspectiva de reconhecimento dele como pilar de sustentação do sistema, junto a outras formas de trabalho não remunerado, como a servidão e a escravidão. Seu livro mais famoso é Calibã e a Bruxa (2017). Como uma das fundadoras do movimento Wages for Housework, em O Ponto Zero da Revolução..., a autora pretende realizar um resgate dos debates a respeito do trabalho doméstico e de sua importância no entendimento e no combate

${ }^{5}$ É importante ressaltar que, como será possível observar ao longo da obra, esta condição específica de abandono do lar rumo à independência financeira, à inserção e à relativa equiparação ao homem branco no mercado de trabalho refere-se à realidade de mulheres brancas de classe média. A vida das mulheres não-brancas, como destaca bell hooks, estrutura-se de uma forma totalmente diferenciada. Estas já ocupam o mercado de trabalho de maneira subalterna como empregadas, babás, secretárias, prostitutas. Ao criticar A mística feminina, hooks afirma: "Problemas e dilemas específicos de donas de casa brancas da classe privilegiada eram preocupações reais, merecedores de atenção e transformação, mas não eram preocupações políticas urgentes da maioria das mulheres, mais preocupadas com a sobrevivência econômica, a discriminação étnica e racial etc. Quando Friedan escreveu $A$ mística feminina, mais de um terço de todas as mulheres estava na força de trabalho. Embora muitas desejassem ser donas de casa, apenas as que tinham tempo livre e dinheiro realmente podiam moldar suas identidades segundo o modelo da mística feminina" (Cf. hooks, bell. Mulheres negras: moldando a teoria feminista. Revista Brasileira de Ciência Política, n. 16, p. 193-210, 2015). 
Cadernos de Clio, Curitiba, v. 9, nº 1, 2018

ao sistema capitalista e colonialista, questionando a natureza da imposição do trabalho doméstico às mulheres bem como suas implicações de subordinação e exploração às vidas sociais delas.

$\mathrm{Na}$ primeira parte do livro, o argumento central de Federici em relação à exploração das mulheres e do trabalho doméstico se dá em razão da ação de um Estado que acumula capital por meio da associação dessa atividade à natureza feminina. Através do pressuposto de que o trabalho doméstico é intrínseco à natureza da mulher, a lógica capitalista a coloca como uma base na organização do trabalho dentro da instituição familiar. Segundo Mariarosa Dalla Costa e Selma James, autoras que exerceram grande influência na constituição e no embasamento das ideias de Federici, a nuclearização da família constitui uma fábrica social, na qual a mulher como mão-de-obra não remunerada é fundamental para a produção da força de trabalho, através de funções produtivas e reprodutivas, que nesse ponto encontram-se indissociáveis. As autoras também argumentam sobre a necessidade de seguir um caminho cada vez mais subversivo à lógica do sistema, defendendo a autonomia dos próprios corpos, que foi confiscada pelo capital. Utilizando a biologia feminina a seu favor, além de ele transformar a relação das mulheres com seus maridos e crianças, converte suas criações em trabalho produtivo com finalidade de acumulação por parte do sistema.

Desse modo, nota-se que tanto Federici quanto Dalla Costa e James defendem a remuneração feita pelo Estado como uma medida essencial para que seja possível negar a naturalização do trabalho doméstico como 
feminino, minando então a lógica capitalista, dando autonomia às mulheres para recusá-lo e abrindo caminhos para uma superação do sistema.

Esta luta pelo salário pago pelo Estado, no entanto, foi tida como menor pelo feminismo, que se voltou para o direito de trabalhar fora, por exemplo. As liberais viam isso como a chance de obter uma carreira e as socialistas, de se incorporarem à luta de classes. A autora destaca, porém, que a luta deveria ser pela independência econômica, não pelo trabalho em si. As mulheres já trabalhavam em casa, necessitando, assim, de mais tempo, não de mais trabalho. Além disso, essa postura pode ter contribuído para um afastamento das donas de casa de movimentos feministas. ${ }^{6}$ Desse modo, o problema do trabalho doméstico - compartilhado por todas as mulheres - não foi resolvido: poucas conseguiram realmente dividir as tarefas com os maridos, passando a exercer jornada dupla e ficando mais cansadas.

A "solução" para tal problema apareceu com o neoliberalismo e a Nova Divisão Internacional do Trabalho (NDIT), marcada pela

${ }^{6}$ Esse afastamento das donas de casa em relação ao feminismo, por sua vez, é um fenômeno predominantemente estadunidense e europeu. Nos anos 1970, muitos países latino-americanos, por exemplo, estavam sob brutais ditaduras militares. Verónica Schild, doutora em Ciência Política com pesquisas sobre mobilizações feministas e impactos do neoliberalismo no Chile, destaca que, nesses lugares, o feminismo adquiriu outros contornos: organizadas em diferentes grupos de mulheres, mobilizaram-se contra os regimes autoritários desde militantes de esquerda a ativistas católicas. Além de haver um engajamento com o feminismo "tradicional" devido à conjuntura política, há outra diferença fundamental: "Em contraste com a 'dona de casa' típica do pós-guerra nos países da OCDE, a maioria das latino-americanas trabalhava - na terra ou como empregadas domésticas -, enquanto as mulheres da elite eram liberadas do trabalho doméstico por suas criadas." (2017: 101). 
globalização, em que o principal envio do "Terceiro Mundo" para o "Primeiro" é o trabalho via migração. Assim, enquanto mulheres europeias trabalham fora, contratam imigrantes para fazer o trabalho doméstico. Essa resolução problemática, além de criar uma relação criada-madame, acentua a tendência da má remuneração para esse trabalho e tira a responsabilidade do homem de fazê-lo. Ademais, é um processo doloroso para as empregadas, que abandonam suas famílias para cuidarem de outras. Teresa Lisboa $^{7}$ trata do tema com mais detalhes, destacando problemas como o abuso sexual por parte de patrões e a dificuldade de ter acesso a serviços públicos em virtude da imigração ilegal. Federici destaca que a política da NDIT visa a transferir a reprodução da mão de obra do Norte para as mulheres do Sul Global. Isso acontece nos processos de barrigas de aluguel, por exemplo, que permitem que mulheres do Norte tenham filhos sem interromper suas carreiras nem arriscar a saúde, além de beneficiar financeiramente os governos. A autora conclui que a NDIT não é emancipatória, pois explora as mulheres ainda mais e reabilita a imagem de reprodutora e objeto sexual, de modo que as políticas feministas precisam ser anticapitalistas e subverter essa nova divisão.

Na sequência, Federici aprofunda suas análises acerca do processo de estruturação do neoliberalismo ${ }^{8}$ e de seu papel como desarticulador de

7 Teresa Kleba Lisboa é doutora em Sociologia e pesquisadora das áreas de violência de gênero, de participação das mulheres no mundo social do trabalho e de equidade de gênero nas políticas públicas.

8 No que se refere ao envolvimento teórico da autora com a temática do neoliberalismo, mostra-se interessante contextualizar suas produções em relação a demais obras que perpassam o tema: os capítulos de $O$ Ponto Zero da Revolução 
direitos e serviços essenciais às mulheres: essa corrente se estabeleceu na década de 1970 como fruto das crises econômicas ocorridas no período, bem como da percepção de ameaça representada por movimentos sociais antissistêmicos (negro, anticolonial e feminista), que se opunham ao enriquecimento estatal através da remuneração nula ou irrisória às atividades (re)produtivas que exerciam. A resposta dos Estados se deu, contudo, em direção à acentuação da responsabilização dos indivíduos por suas necessidades de subsistência, bem como, no Sul Global, à intensificação de políticas arbitrárias de austeridade. Ou seja, serviços

que abordam aspectos do sistema neoliberal foram escritos entre os anos 1990 e 2000. Nesse período, e principalmente nos anos subsequentes a ele, registrou-se extensa produção acadêmica dedicada a analisar processos constitutivos do neoliberalismo e as consequências dele para o funcionamento de diferentes sociedades. Inserem-se aí obras de pensadoras estadunidenses como Nancy Fraser e Wendy Brown. Ambas apresentam pontos de confluência com as ideias de Federici, caracterizando esse sistema como extenso, não restrito a uma esfera econômica, mas sim permeador das diversas bases do cotidiano social, acarretando desmantelamento de serviços essenciais à coletividade, precarização do mundo do trabalho e a instituição de um modelo mental coletivo de "empresariamento de si mesmo" (ou "razão neoliberal", nos termos da segunda autora). Fraser (2019) defende a superação da crise generalizada vivenciada hoje por meio de uma transformação sistêmica completa a ser encabeçada por mobilizações populares, nas quais estaria incluso um "feminismo para os 99\%", anticorporativo. Já Brown (2015), em contraponto às constatações de Federici acerca da necessidade de transformação absoluta do modo de vida capitalista e de sistemas políticos que não asseguram protagonismo às coletividades e acesso a recursos "comuns", apresenta considerações mais reformistas, afirmando que as democracias liberais, apesar de burguesas, deveriam ser conservadas por servirem como propulsoras iniciais de anseios mais amplos por liberdade e direitos. Para saber mais, verificar: FRASER, Nancy. The old is dying and the new cannot be born: From progressive neoliberalism to Trump and beyond. New York: Verso Books, 2019; e BROWN, Wendy. Undoing the demos: Neoliberalism's stealth revolution. New York: Mit Press, 2015. 
essenciais de saúde, educação e previdência deixaram de receber investimentos públicos, acarretando escalada da sobrecarga de serviços de cuidado já atrelados aos corpos femininos. Em relação a tais problemáticas, a autora suscita discussões teórico-conceituais e enfatiza o teor revolucionário da expressão "trabalho reprodutivo", questionando os paradigmas marxistas tradicionais. Esses são criticados por Federici na medida que não só deixavam de considerar as tarefas de cuidado como parte do processo de produção das forças de trabalho, supostamente restrito ao consumo de mercadorias, como também centralizavam na figura do proletário europeu urbano o protagonismo da produção material e, consequentemente, das lutas anticapitalistas.

Complementando suas críticas às realidades neoliberais instituídas a partir dos anos 1970, a autora chama atenção para a posição assumida nesse período pela ONU. Em adição aos desmantelamentos de sistemas sociais e às espoliações de recursos naturais realizados, a instituição passou a exercer postura de controle indireto da radicalidade feminista por meio da cooptação de suas pautas e lideranças. A criação de espaços institucionais para debates de gênero, com o desenvolvimento de programas impulsionadores da agenda do Banco Mundial e a secundarização das lideranças de países não hegemônicos frente às "feministas profissionais" dos EUA, propiciou alinhamento de parte do movimento com causas neoliberais e decorrente afastamento da organicidade popular registrada inicialmente nas reivindicações feministas. Tal fenômeno é destrinchado por Veronica Schild, que argumenta que a fenda de serviços básicos 
deixada pelos Estados foi preenchida, no contexto latino-americano, por ONGs patrocinadas pela ONU. Essas, ao invés de dialogarem com organizações locais já existentes, priorizaram gestões de feministas acadêmicas e políticas, vinculadas a instituições estrangeiras, invalidando, com isso, possibilidades de ativismos regionais e autenticamente revolucionários.

$\mathrm{Na}$ terceira parte da obra, Federici apresenta uma das questões mais importantes às pautas de gênero e ao mundo do trabalho: o acesso à terra, eixo relevante para se pensar a construção de uma sociedade mais solidária e comunitária. A autora inicia sua abordagem sobre essa temática analisando historicamente as investidas dos setores capitalistas no sentido de retirar da população, especialmente feminina, o acesso à terra e, consequentemente, a sua subsistência. A partir desse momento, as comunidades locais empobreceram e tornaram-se dependentes de recursos pertencentes ao grande capital, os quais não são acessíveis a todos em uma sociedade desigual como a que é encontrada em diferentes níveis no planeta. Dessa forma, a partir de um posicionamento que identifica historicamente as mulheres como as agentes de vanguarda na luta pela manutenção das terras comunais e contra o capital, Federici infere que uma das mais eficazes formas de construção de uma sociedade mais equilibrada e que incentive a solidariedade e não a competitividade é a luta por terras comunais e práticas de subsistência. 
Ademais, é importante mencionar que essa é uma pauta defendida tanto por diversos intelectuais e lideranças sociais ${ }^{9}$ quanto por comunidades que, mesmo que alheias às discussões acadêmicas, entendem a importância da manutenção desses sistemas e da luta por mais áreas agricultáveis. $\mathrm{O}$ antropólogo Arturo Escobar, em sua obra La invención del Tercer Mundo: construcción y desconstrucción del desarrollo, analisa essa mesma problemática destacando a forma como as organizações internacionais e países desenvolvidos mantêm suas políticas neocoloniais por meio da expulsão de populações originárias de suas terras e do estabelecimento de relações de dependência dos mercados interno e externo, o que as aliena dos meios produtivos para sua subsistência. Dessa forma, ambos os autores, além de externarem suas críticas a essas práticas violentas, também ressaltam exemplos bem sucedidos de resistência e luta, apontando caminhos a seguir para garantir um melhor futuro, enfatizando, assim, os caminhos comunitários e solidários, não individualizados.

${ }^{9}$ É possível estabelecer relações entre essas reflexões da autora e as práticas de feminismo comunitário encontradas em países latino-americanos: o pensamento do feminismo comunitário é bastante amplo e tem diversas ramificações, como o empregado pelas mulheres trabalhadoras na Bolívia. Na comunidade Mujeres Creando, o feminismo comunitário começa epistemologicamente empregando a descolonização do próprio feminismo, partindo do pressuposto que esse carrega consigo diversas formas de opressão, principalmente originários do sistema capitalista de produção. Para além desse esforço, as próprias categorias de gênero e patriarcado são repensadas. Tal discussão relaciona-se ao conceito de comuns de Frederici, na medida em que, para se atingir as expectativas postas sob a construção de uma sociedade comunitária, devem-se rever os conceitos estruturantes que a sustentam. Para saber mais, verificar: PAREDES, Julieta. El feminismo comunitario: la creación de un pensamiento propio. Corpus, vol. 7, n. 1, 2017. 
Tomando como base os principais pontos levantados neste texto, ponderamos que $O$ Ponto Zero da Revolução... se revela uma obra extremamente relevante para os dias atuais, especialmente no Brasil, em que vemos um movimento amplo e articulado de desmonte das políticas públicas, direitos trabalhistas e implemento das faces mais radicais e violentas do neoliberalismo. Dessa forma, o livro nos fornece importantes discussões e exemplos concretos de populações que, enfrentando questões tão críticas quanto, rebelaram-se e lutaram por um futuro menos desigual e pela construção de uma sociedade que desnaturalizasse a competição, o lucro e a violência. Consideramos fundamental notar o papel renovador e transgressor que a obra exerce dentro de seu contexto de publicação ao se levar em conta, para além do cenário nacional, os horizontes de produção teórica feminista. Nas últimas décadas, por conta da difusão de discursos eminentemente reificadores do neoliberalismo do Norte - seja através de meios virtuais, seja pelo fortalecimento de uma cultura de "feminismo de advocacy" - , ainda que esse movimento social tenha alcançado maior aceitação entre diferentes parcelas populacionais, vem atravessando processo de banalização de suas pautas. Nesse sentido, as recuperações históricas levantadas por Federici, junto a suas elaborações acerca das problemáticas dos sistemas "piramidais" instaurados sob slogan de suposta “cooperação internacional" pela globalização e à sua marcante tese de necessidade de questionamento das estruturas de reprodução social normalizadas sob o capitalismo, permitem que os públicos leitores do Sul Global, como conjunto de indivíduos que partilha das heranças racistas, 
Cadernos de Clio, Curitiba, v. 9, nº 1, 2018

coloniais e patriarcais instituídas externamente, continuem e ampliem a articulação de mobilizações feministas capazes de subverter estacas político econômicas exploratórias. A busca por concretização das emancipações de grupos historicamente subjugados, com destaque para a efetiva liberação das mulheres, é nitidamente instigada por Federici, em um movimento que contribui para o fortalecimento das resistências feministas latino-americanas antissistêmicas. No passado e ainda hoje, essas têm estado voltadas à conquista de direitos reprodutivos, à redução da violência de gênero e à retomada dos "comuns" por amplas parcelas populares.

\section{Bibliografia}

DALLA COSTA, Mariarosa; JAMES, Selma. The Power of Women and the Subversion of the Community. Bristol: Falling Wall Press, 1975.

ESCOBAR, Arturo. La invención del Tercer Mundo: construcción y desconstrucción del desarrollo. Caracas: Fundación Editorial el perro y la rana, 2007.

LISBOA, Teresa Kleba. Fluxos migratórios de mulheres para o trabalho reprodutivo: a globalização da assistência. Revista Estudos Feministas, Florianópolis, v. 15, n. 3, p. 805-821, set./dez. 2007.

SCHILD, Verónica. Feminismo e neoliberalismo na América Latina. Nueva sociedad, Buenos Aires, Edição Especial, p. 98-113, jun. 2017.

Recebido em: 03/06/2020

Aceito em: 20/07/2020 